\title{
Estilos de Implementação e Resultados de Políticas Públicas: Fiscais do Trabalho e 0 Cumprimento da Lei Trabalhista no Brasil ${ }^{*}$
}

\author{
Roberto Rocha C. Pires
}

\section{INTRODUÇÃO}

É fato que a maior parte da atenção pública e da energia política se concentra nos momentos e nas decisões relativas à formulação de novas políticas públicas e leis (ou na reforma destas). Muito frequentemente esses momentos são apresentados como conquistas importantes, avanços ou até soluções para alguns dos problemas que assolam o Brasil. Contudo, quando observamos mais de perto a implementação de algumas dessas políticas públicas (seja na área social, seja na segurança pública, na regulação etc.), não é incomum ficarmos frustrados com seus resultados ou constatarmos que os resultados de uma mesma política implementada, em um mesmo local (país, estado ou município), por uma mesma organização, sejam heterogêneos - isto é, os obje-

\footnotetext{
* Uma versão anterior deste artigo foi apresentada no Grupo de Trabalho (GT) de Políticas Públicas do $32^{\circ}$ Encontro Anual da Associação Nacional de Pós-Graduação e Pesquisa em Ciências Sociais (Anpocs), em outubro de 2008, realizado em Caxambu, Minas Gerais. Agradeço aos participantes do GT, em especial a Eduardo Marques, assim como aos pareceristas anônimos da revista $D A D O S$, os comentários e sugestões. Essa pesquisa é um desdobramento de um projeto iniciado no Massachusetts Institute of Technology (MIT) em 2006, com o título The Rule of Law, Economic Development, and the Modernization of the State in Brazil: Lessons from Existing Experience for Policy and Practice, supervisionado por Judith Tendler e financiado pelo escritório do Ministério Britânico para o Desenvolvimento Internacional e pelo Banco Mundial, ambos em Brasília. Finalmente, agradeço a todas as pessoas que gentilmente concordaram em ser entrevistadas para esta pesquisa. Aplicam-se aqui as ressalvas de praxe.
}

DADOS - Revista de Ciências Sociais, Rio de Janeiro, Vol. 52, n-3, 2009, pp. 735 a 769. 
tivos formais ou iniciais de uma política não são alcançados da mesma forma em todos os lugares. Por exemplo, o cumprimento da legislação ambiental é maior em algumas localidades do que em outras; em algumas regiões de um município, equipes do Programa Saúde da Família (PSF) produzem melhores resultados do que em outras. O que explica essa variação? Por que sistemas burocráticos não implementam políticas de modo uniforme e objetivo, assim como previsto na perspectiva weberiana?

A literatura especializada aponta muitos fatores que potencialmente afetam a variação nos resultados de uma política pública (por exemplo, renda/desenvolvimento local, organização da sociedade civil, redes sociais, competição entre elites locais/regionais etc.). No entanto, pouco se sabe sobre o efeito das decisões, práticas e comportamentos de agentes burocráticos sobre os resultados das políticas públicas. Haveria alguma relação entre estilos de implementação adotados por esses agentes e os resultados de uma política?

Para abordar essa lacuna, no presente estudo é examinada a política de inspeção do trabalho no Brasil, à qual compete a implementação e/ou a verificação do cumprimento da legislação trabalhista, com o intuito de explorar se e como a variação nas práticas e nas condutas de agentes burocráticos de linha de frente explica a variação nos resultados obtidos. Para isso, além desta introdução e da conclusão, o artigo está dividido em três partes.

Primeiramente, apresenta-se uma revisão da literatura sobre implementação de políticas públicas (sua emergência e evolução como subcampo de estudos) e identifica-se uma lacuna teórico-empírica importante: a ausência de estudos que compreendam os elos causais entre variação em estilos/práticas de implementação e resultados de políticas públicas. Na segunda seção, apresenta-se a estratégia metodológica (e técnicas de análise comparativa empregadas), além de como se pretende avançar em direção ao preenchimento dessa lacuna, com base em extensa pesquisa de campo sobre a implementação da legislação trabalhista no Brasil. Na terceira parte, partindo de três padrões de resultado da intervenção dos fiscais do trabalho, ilustrados a partir de exemplos empíricos, é estabelecida a variação nos resultados da política de inspeção do trabalho. Em seguida, são apresentados os resultados da análise comparativa que visou avaliar os potenciais elos causais entre estilos de inspeção e resultados em termos do cumprimento 
da lei trabalhista por parte de empregadores e empregados. Por fim, na conclusão são apresentadas as principais implicações deste estudo para o campo das políticas públicas.

\section{IMPLEMENTAÇÃO, IMPLEMENTADORES E ESTILOS DE IMPLEMENTAÇÃO: O DEBATE NA LITERATURA}

Há décadas pesquisadores têm se dedicado a compreender o "problema da implementação". Em parte da Europa e na América do Norte, o planejamento racional-compreensivo, triunfante nos anos 1950-1960, conduzido por tecnocracias estatais em expansão desde o período entre guerras, deparou-se com forte ceticismo a partir da década de 1970. A decepção em relação ao desempenho do Estado crescia à medida que os resultados insatisfatórios de políticas e programas se tornavam mais aparentes e recorrentes. Paralelamente às críticas ao Estado, advindas tanto da esquerda (Estado capturado e não responsivo) quanto da direita (Estado invasivo e ineficiente), ocorriam avanços no campo dos estudos organizacionais (por exemplo, a "racionalidade limitada", de Simon e March, 1958) que abriram o caminho nos anos 19701980 para o debate acadêmico sobre implementação de políticas públicas motivado pela seguinte questão: por que observamos tanta discrepância entre os objetivos planejados e os alcançados?

O estudo de Pressman e Wildavsky (1973) sobre a Agência de Desenvolvimento Econômico de Oakland (e o fomento ao emprego de minorias) é um dos marcos fundadores do campo de estudos sobre implementação no debate norte-americano. Esses pesquisadores elegeram para o estudo uma política que, em tese, tinha tudo para ser bem-sucedida: os recursos estavam garantidos, havia consenso entre as várias esferas de governo envolvidas e o setor privado, o desenho institucional era considerado inovador e tecnicamente viável, entre outros atributos. Contudo, o projeto não foi implementado dentro do cronograma esperado e não gerou os resultados almejados. Segundo os autores, a explicação para o fracasso da iniciativa reside em elementos mais prosaicos, que pertencem ao cotidiano da execução de políticas (em oposição a fatores externos como os mencionados anteriormente). Pressman e Wildavsky constataram que o processo de implementação de políticas públicas envolve necessariamente complexidades (critérios contraditórios, acomodação de interesses conflitantes, múltiplos atores, processos decisórios longos e tortuosos etc.) muito maiores do que o debate do período poderia supor: 
[...] quando dizemos que os programas falharam, damos a impressão de que estávamos surpresos. Se pensássemos desde o início que tais ações tinham de fato poucas chances de ser bem-sucedidas, o insucesso delas em realizar as metas propostas ou de gerar quaisquer resultados não demandaria nenhum tipo de explicação especial (ibidem:87; tradução do autor).

Seguindo essa mesma linha, outros autores enfatizaram o processo de implementação como uma etapa difícil e complexa da realização de políticas públicas. Bardach (1977), por exemplo, desenvolveu uma tipologia de "jogos de implementação" que enfatiza os processos e os constrangimentos institucionais que criam oportunidades para desvio de recursos, atrasos, distorção e não realização de objetivos almejados. Segundo o autor, somente a simplificação de políticas ainda na etapa de seu desenho poderia evitar os problemas da implementação: "quanto menos etapas envolver o processo de implementação, menores são as oportunidades para o desastre" (ibidem:250; tradução do autor).

Já a partir dos anos 1980, surge outra resposta ao problema da discrepância entre objetivos e resultados alcançados que enfatiza a natureza necessariamente política do processo de implementação. Pesquisadores nessa linha questionaram a percepção da implementação como um processo (policy cycle) mecânico, linear e complexo de tradução de metas em rotinas de operação. Em vez disso, argumentaram que a etapa de implementação diz respeito a questões, conflitos e decisões fundamentais sobre "quem recebe o quê?". Os estudos de Grindle e Thomas (Grindle e Thomas, 1989; Thomas e Grindle, 1990), Allison (1969), Nakamura e Smallwood (1980), e BID-IPES (2006) chamaram a atenção para como barganhas - em torno de recursos administrativos, poder e diferentes visões sobre uma política - entre gestores públicos, elites políticas e grupos interessados afetam e constantemente remodelam os objetivos e os formatos organizacionais de políticas e programas.

Finalmente, uma terceira linha de pesquisa desagregou o Estado e suas organizações para chamar a atenção para o papel desempenhado por burocratas de linha de frente (street-level bureaucrats) e a influência destes na performance e na redefinição dos objetivos de uma política pública (Lipsky, 1980; Wilson, 1968; 1989; Silbey, 1981; 1984; Silbey e Bittner, 1982; Tendler, 1997; Maynard-Moody e Musheno, 2003) ${ }^{1}$. Essa resposta ao "problema da implementação" introduziu uma mudança paradigmática, visto que chamou a atenção para o papel crucial desenvolvido 
por atores até então ignorados nas avaliações de políticas públicas. De acordo com essa vertente, burocratas de linha de frente gozam inevitavelmente de um alto grau de discricionariedade (em virtude da escassez de recursos, de objetivos ambíguos, de dificuldade de supervisão etc.) na tomada de decisões sobre como implementar a política ${ }^{2}$. Por consequência, não se pode compreender a implementação de políticas e o desempenho organizacional sem considerar as regras, pressões e situações vivenciadas pelos funcionários de linha de frente (professores, policiais, fiscais etc.) durante o cotidiano de seu trabalho ${ }^{3}$.

Os impactos dessa mudança de paradigma foram consideráveis. Primeiramente, em relação aos defensores do planejamento racionalcompreensivo das décadas anteriores (1950-1960), essa linha de pesquisa contribuiu para a consolidação dos avanços na teoria organizacional (por exemplo, racionalidade limitada, satisficing vs. maximizing, incertezas, informação imperfeita etc.), no estudo da implementação de políticas públicas. Em segundo lugar, ao chamar a atenção para o lugar do indivíduo na burocracia (e para o burocrata de linha de frente como ator relevante no processo de realização da política pública), essa abordagem demonstrou que o Estado não é um ator unitário, mas sim fragmentado de cima a baixo, complicando os argumentos neomarxistas sobre a captura do Estado (muitas facções a serem capturadas pelos mesmos interesses). Em terceiro lugar, essa linha consolidou-se, a partir da década de 1990, em uma literatura que se dedicou a investigar a fundo a estrutura interna do Estado (Wilson, 1989; Hawkins, 1992; Tendler, 1997; Justice, 1986; Joshi, 2000; Bianchi, 2002; MaynardMoody e Musheno, 2003; Crook e Ayee, 2006; entre outros).

Em suma, essa terceira resposta ao "problema da implementação" apresenta, como contribuição definitiva, a abertura do espaço para o vislumbramento de diferentes práticas e estilos de implementação a partir do fracionamento de burocracias públicas. Entretanto, essa abordagem ainda avançou muito pouco no sentido da exploração e do estabelecimento de nexos causais entre variação nas formas ou nos estilos de implementação adotados por burocratas de linha de frente e os resultados de políticas observados ${ }^{4}$.

\section{IMPLEMENTAÇÃO DA LEGISLAÇÃO TRABALHISTA NO BRASIL: COMPREENDENDO A VARIAÇÃO NOS RESULTADOS}

Com o objetivo de preencher a lacuna anterior identificada na literatura e avaliar se e como estilos de implementação afetam os resultados de 
uma política pública, o presente estudo debruçou-se sobre uma política pública específica, implementada por uma única organização: a inspeção do trabalho. A fiscalização do cumprimento da legislação trabalhista e das normas de segurança e saúde do trabalho no Brasil compete à Secretaria de Inspeção do Trabalho (SIT), no Ministério do Trabalho e Emprego (MTE).

A fiscalização exercida pela SIT-MTE integra, por força da Constituição de 1988, com o Ministério Público do Trabalho (MPT) e a Justiça do Trabalho, um "tripé" institucional para proteção e garantia dos direitos trabalhistas. Por um lado, o MPT e a Justiça do Trabalho, respectivamente, incitam e julgam processos judiciais reforçando ou criando novas interpretações da lei à medida que esses órgãos fortificaram suas capacidades de intervenção na produção da regulação do trabalho a partir da década de $1990^{5}$. Por outro lado, cabe à inspeção do trabalho a tarefa de "polícia administrativa", por meio da fiscalização contínua de ambientes de trabalho e da autuação imediata dos infratores da lei (multas administrativas). Visando ao cumprimento de tal função no âmbito desse ambiente institucional, a SIT-MTE elabora as diretrizes nacionais de inspeção e supervisiona as atividades de aproximadamente 3.000 auditores-fiscais do trabalho distribuídos em 27 Superintendências Regionais de Trabalho e Emprego (SRTEs) ${ }^{6}$.

Esse contingente de auditores-fiscais do trabalho (AFTs) tem a missão de cobrir mais de 78 milhões de trabalhadores ocupados (em empregos formais e informais) e 2,7 milhões de empresas registradas em todos os 5.564 municípios brasileiros ${ }^{7}$. Além disso, esses AFTs lidam com a complexidade técnica envolvida na fiscalização dos 922 artigos da CLT (Consolidação das Leis do Trabalho), de 46 artigos da Constituição Federal, 79 convenções da OIT, 30 normas de saúde e segurança (que somam mais de dois mil itens), e muitos outros atos administrativos e decisões judiciais. Além das proporções e da complexidade da tarefa, os AFTs realizam a maior parte de seu trabalho inspecionando empresas em campo, geralmente mediando, sob tensão e escassez de recursos administrativos (computadores, veículos etc.), conflitos de interesses. Por todas essas razões, os fiscais do trabalho correspondem ao perfil do burocrata de linha de frente típico e, consequentemente, gozam de alto grau de discricionariedade no exercício de suas funções. Para esses agentes, é impossível cobrir o universo de empresas/trabalhadores e todos os regulamentos, e não existe uma forma única de aplicar a legislação para todo o mercado de trabalho. Assim, esses agentes ine- 
vitavelmente têm de: a) escolher que empresas ou setores vão enfocar e como vão interagir com eles; b) selecionar os problemas que merecem mais atenção e priorizá-los; c) improvisar e desenvolver abordagens e soluções específicas e adequadas aos problemas de cada setor ou caso particular.

Essa situação oferece o contexto ideal para a avaliação da existência de estilos de implementação e de seus impactos sobre o resultado de políticas. Nesse sentido, no presente estudo foi utilizada uma metodologia que combinou pesquisa de campo com técnicas de análise comparativa. Mediante extensa pesquisa de campo (coleta de dados, documentos, participação em reuniões e 114 entrevistas com os diversos atores envolvidos entre dezembro/2006 e agosto/2008), foram reunidas informações sobre 24 casos nos quais fiscais do trabalho intervieram em diversas atividades econômicas e contextos sociais, sobretudo em três estados: Minas Gerais, Bahia e Pernambuco ${ }^{8}$. Desse total de entrevistas, aproximadamente 49 foram realizadas com fiscais do trabalho nos três estados e no nível central, em Brasília. Durante as entrevistas, solicitou-se aos fiscais que relatassem, com base em suas próprias experiências ou na experiência de colegas, casos envolvendo resultados positivos e casos que resultaram em impasse. A identificação dos casos foi consolidada por meio de triangulação, entrevistando-se outros 65 atores relevantes envolvidos em cada caso específico, incluindo empresários, gerentes, trabalhadores e sindicatos, associações empresariais e outros órgãos públicos (Fundacentro; MPT; bancos de desenvolvimento; entre outros).

A partir da sistematização das informações coletadas, a primeira etapa da análise focou as comparações entre casos (cross-case) para determinar os padrões de resultado existentes entre os diferentes casos e contextos. O Quadro 1 apresenta a tipologia de resultados da intervenção dos auditores-fiscais do trabalho. A partir da amostra de 24 casos, foram identificados três padrões distintos de resultado.

O primeiro tipo de resultado diz respeito a situações nas quais os fiscais do trabalho falham no desempenho de sua missão de garantir o cumprimento da lei por parte das empresas. Por exemplo, em 2001, dois anos depois que a Ford iniciou as operações de sua nova montadora em Camaçari (BA), os fiscais do trabalho observaram um aumento de lesões por esforço repetitivo (LER) entre os trabalhadores locais. Contudo, apesar de estarem há mais de quatro anos atuando no caso, 
os fiscais não conseguiram promover muitas mudanças no modo como a montadora operava nem na redução das lesões. Da mesma forma, há muito são conhecidos os danos ambientais causados por empresas de mineração de ardósia e granito em Papagaio (MG), bem como as doenças ocupacionais causadas pela poeira lançada por empresas locais. Nos últimos cinco anos, os fiscais não tiveram sucesso na promoção do cumprimento de itens básicos do código trabalhista nas empresas (a maioria de pequeno porte) que atuam naquela área.

O segundo tipo de resultado se refere a situações nas quais os fiscais do trabalho conseguiram promover o cumprimento da lei, mas à custa da produtividade ou da competitividade das empresas. Essa categoria exemplifica a suposta incompatibilidade entre direitos trabalhistas e desempenho das empresas, porque a regularização geralmente leva ao aumento dos custos de produção. Consequentemente, as empresas encontram pouco incentivo para continuar regulares ao longo do tempo, exceto pela ameaça contínua de sanções que provavelmente não continuarão a ser aplicadas por muito tempo, dada a limitação de recursos dos reguladores. Por exemplo, desde meados da década de 1990, os fiscais do trabalho têm tido dificuldade em coibir a terceirização das atividades-fim das empresas (em contraste com as atividades-meio, ou administrativas) para cooperativas de trabalhadores, o que é considerado um desvio ilegal dos requisitos da legislação trabalhista. Em Reci$\mathrm{fe}$, as empresas de informática têm argumentado que empregar diretamente todos os trabalhadores (especialmente os projetistas de software que recebem por produto desenvolvido) seria não somente ineficiente mas também muito custoso. Consequentemente, recorriam às cooperativas de trabalhadores como uma maneira de reduzir custos e conferir mais flexibilidade (por exemplo, carga horária) a seus projetistas. Ao proibir as empresas de lançar mão dessas cooperativas, os fiscais do trabalho conseguiram fazer com que elas cumprissem a lei. Entretanto, conforme destacaram alguns empresários, basta que o fiscal pare de inspecionar para que elas voltem ao arranjo das cooperativas de trabalhadores (ou outro arranjo semelhante para evitar os encargos trabalhistas). Como dizem os empresários, é mais barato pagar os custos das multas, caso eventualmente sejam pegos pelos fiscais, do que arcar com o custo de empregar todos os trabalhadores diretamente.

Finalmente, há um terceiro tipo de resultado, denominado "cumprimento sustentável da lei". Nesses casos, os fiscais promovem com sucesso a compatibilização das normas trabalhistas com o desenvolvi- 


\section{Quadro 1}

Tipos de Resultado e Casos

\begin{tabular}{|c|c|}
\hline 1 & Número de Obse \\
\hline $\begin{array}{l}\text { 1. Não cumprimento da } \\
\text { lei: } \\
\text { A intervenção dos fiscais } \\
\text { do trabalho não resultou } \\
\text { em aumento significativo } \\
\text { do nível de conformidade } \\
\text { com a lei por parte das } \\
\text { empresas. }\end{array}$ & $\begin{array}{l}6 \text { observações ( } 25 \% \text { ): } \\
\text { - Telemarketing, Belo Horizonte (MG). } \\
\text { - LER, montadora Ford, Camaçari (BA). } \\
\text { - Mineração de pedras ornamentais, São Tomé das Le- } \\
\text { tras e Papagaio (MG). } \\
\text { - Mineração de pedras ornamentais (ES). } \\
\text { - Plantio e beneficiamento de sisal, Valente e região } \\
\text { (BA). } \\
\text { - Produção de fogos de artifício, Santo Antônio de Jesus } \\
\text { (BA). }\end{array}$ \\
\hline $\begin{array}{l}\text { 2. Cumprimento da lei: } \\
\text { A intervenção dos fiscais } \\
\text { do trabalho teve sucesso } \\
\text { em fazer as empresas } \\
\text { cumprirem a lei imediata- } \\
\text { mente, mas não criou con- } \\
\text { dições favoráveis para } \\
\text { que as empresas continu- } \\
\text { assem em conformidade } \\
\text { com a lei. }\end{array}$ & $\begin{array}{l}8 \text { observações ( } 33 \% \text { ): } \\
\text { - Produção de carvão vegetal e reflorestamento, Cama- } \\
\text { çari (BA). } \\
\text { - Produção de cerâmicas, Camaçari (BA). } \\
\text { - Inspeção rural no oeste baiano (BA). } \\
\text { - Cooperativas de trabalho na indústria do software, Re- } \\
\text { cife (PE). } \\
\text { - Indústria de calçados, Jequié (BA). } \\
\text { - Construção civil, Belo Horizonte (MG). } \\
\text { - Indústria de calçados, Nova Serrana (MG). } \\
\text { - Mineração de ouro (Morro Velho), Nova Lima (MG). }\end{array}$ \\
\hline $\begin{array}{l}\text { 3. Cumprimento susten- } \\
\text { tável da lei: } \\
\text { A intervenção dos fiscais } \\
\text { do trabalho não apenas } \\
\text { fez com que as empresas } \\
\text { cumprissem a lei, mas } \\
\text { também criou soluções le- } \\
\text { gais e/ou técnicas que } \\
\text { funcionaram como incen- } \\
\text { tivos positivos para que } \\
\text { as empresas permaneces- } \\
\text { sem em conformidade. }\end{array}$ & $\begin{array}{l}10 \text { observações (42\%): } \\
\text { - Carnaval (cordeiros), Salvador (BA). } \\
\text { - Produção de grãos e sementes, Paracatu/Unaí (MG). } \\
\text { - Indústria de autopeças, região metropolitana de Belo } \\
\text { Horizonte (MG). } \\
\text { - Produção de fogos de artifício, Santo Antônio do } \\
\text { Monte (MG). } \\
\text { - Galvanização - indústria automobilística, região do } \\
\text { ABC (SP). } \\
\text { - Indústria de autopeças, região do ABC (SP). } \\
\text { - Grupo móvel especial do trabalho escravo (PA). } \\
\text { - Celulose e papel - sul da Bahia. } \\
\text { - Indústria petroquímica (benzeno), Camaçari (BA). } \\
\text { - Mineração de minério de ferro, Itabira/Brucutu (MG). }\end{array}$ \\
\hline
\end{tabular}

Elaboração do autor. 
mento econômico. Isto é, fazem com que as empresas cumpram a lei ao mesmo tempo que encontram soluções legais e/ou técnicas que criam incentivos positivos para que elas aprimorem suas atividades produtivas, condições de trabalho, e também para que permaneçam em conformidade com a lei. Em alguns dos casos observados mediante a pesquisa de campo, os fiscais criaram novas formas de contratação e arranjos empregatícios, bem como soluções técnicas que tornaram os processos de produção mais seguros e ao mesmo tempo mais eficientes. Essas soluções técnicas e legais, por sua vez, estimularam processos de mudança nas práticas empresariais, assim como facilitaram o encontro entre as normas legais e o desempenho das empresas. Os dois exemplos a seguir ilustram de forma sucinta esse terceiro padrão de resultado":

a) Atualmente, $70 \%$ de todos os trabalhadores rurais assalariados no Brasil são informais (alcançando até $85 \%$ na região Nordeste) (IBGE, 2005). Isso ocorre porque produtores rurais em todo o país consideram proibitivos os custos financeiros e administrativos de contratar formalmente, com registro na carteira de trabalho, por exemplo, dois mil trabalhadores safristas para colher feijão por quinze dias ${ }^{10}$. Desse modo, frequentemente, esses produtores recorrem a arranjos ilegais para a contratação desses trabalhadores, como os arregimentadores ou "gatos", a fim de escapar dos custos associados à contratação formal. Porém, a intervenção dos fiscais do trabalho nos pequenos e médios produtores de sementes e grãos da região de Paracatu e Unaí (MG), a partir do fim da década de 1990, demonstra que é possível aumentar o nível de formalização da mão de obra no campo sem que haja aumento significativo do custo de produção. Os fiscais do trabalho implementaram nessa região, em parceria com o MPT, o consórcio, ou condomínio, de empregadores rurais. O consórcio é uma associação formal de produtores rurais individuais em que os membros compartilham responsabilidades solidárias somente para questões trabalhistas. Assim, os consórcios permitem, por um lado, contratação formal, direitos e benefícios para os trabalhadores; por outro, compartilhamento entre os produtores-membros e consequente redução do gasto com encargos trabalhistas (por exemplo, aposentadoria, seguro-desemprego, normas de saúde e segurança do trabalho etc.). Em 2000, a implementação dos consórcios contribuiu para a formalização de 22 mil trabalhadores (Miguel, 2004). No ano seguinte, os números aumentaram para aproximadamente 65 mil 
trabalhadores e 3.500 produtores rurais em 103 consórcios (Zylberstajn, 2003). Atualmente, há mais de 150 consórcios em todo o país, com uma maior concentração em Minas Gerais (46 consórcios nesse estado).

b) No Brasil, ocorrem aproximadamente 410 mil acidentes de trabalho por ano, ou seja, uma média de 1.120 acidentes por dia, dos quais oito são fatais (Baumecker e Faria, 2006). No setor metal-mecânico (especialmente o segmento de autopeças), que emprega 309.400 trabalhadores no Brasil, aproximadamente $70 \%$ dos trabalhadores lidam com máquinas, tais como prensas mecânicas, para a fabricação de componentes a partir de chapas de aço. Os trabalhadores desse setor são frequentemente vítimas de acidentes graves, envolvendo laceração e amputação de dedos, mãos e braços, em virtude da obsolescência e da falta de segurança das prensas em funcionamento. Nas últimas décadas, empresas do setor vêm enfrentando intensa competição doméstica e internacional e, por isso, resistiram à adoção de equipamentos de proteção que poderiam minimizar os riscos de acidentes, em função da perda de produtividade causada por tais complementos (em alguns casos chegando a 30\%). Em 1999, fiscais do trabalho de Minas Gerais atuaram nesse setor desenvolvendo e disseminando a utilização de novos kits de proteção para prensas (que incluíam novos equipamentos, além de técnicas ergonômicas e outras medidas) que minimizaram significativamente a perda de produtividade das prensas. Como resultado, até o fim de 2005, 70\% das 350 empresas inspecionadas na área metropolitana de Belo Horizonte haviam adotado proteção adequada para suas prensas, incluindo a montadora Fiat, que substituiu todas as suas máquinas obsoletas por novas. Em 2003, o número de acidentes oficialmente registrados no setor de autopeças foi reduzido em 66\% em comparação com 2001.

Nesta seção, foi apresentada uma tipologia dos resultados da política de inspeção do trabalho resultante da análise comparativa entre os casos da amostra. Contudo, existe alguma relação entre a variação nos resultados da política de inspeção do trabalho e os estilos de implementação adotados pelos fiscais do trabalho em cada caso? Em outras palavras, por via de que práticas e condutas os fiscais do trabalho promovem o cumprimento sustentável da lei e a compatibilização entre direitos e competitividade? Essas questões são o objeto da próxima seção. 


\section{ESTILOS DE IMPLEMENTAÇÃO E RESULTADOS DE POLÍTICA ${ }^{11}$}

Na segunda etapa da análise, a comparação entre os casos (cross-case) foi complementada por uma maior atenção aos casos bem-sucedidos ("cumprimento sustentável da lei"), os quais foram objeto de uma análise de processo aprofundada (process tracing and within case comparisons $)^{12}$. A combinação dessas diferentes técnicas de análise comparativa visou explorar a existência de potenciais elos causais entre estilos de implementação adotados pelos fiscais do trabalho (variável independente) e os resultados da política de inspeção em termos do cumprimento da lei trabalhista (variável dependente). Como demonstrado a seguir, os resultados dessas análises sugerem uma associação consistente entre os resultados observados e os conjuntos específicos de práticas de inspeção implementadas pelos fiscais do trabalho.

A comparação entre casos revelou variações não apenas em termos dos resultados da política de inspeção do trabalho mas também em termos das estratégias e práticas empregadas pelos fiscais em cada caso. Foi possível identificar três padrões distintos de estilos de implementação que, em grande parte dos casos, tinham forte relação com os resultados. Dois desses estilos observados na amostra de casos de intervenção dos fiscais do trabalho correspondem a dois modelos alternativos já prescritos na vasta e consolidada literatura da sociologia jurídica. No primeiro estilo identificado, a atuação dos fiscais se assemelha com o modelo repressivo, no qual agentes da lei atuam de forma exclusivamente punitiva (multas, interdições etc.), castigando os violadores (Becker, 1968; Stigler, 1971; Ehrlich, 1972; Tullock, 1974; Reiss Junior, 1984; Polinsky e Shavell, 2000; Weil, 2005) ${ }^{13}$. O segundo estilo observado na atuação dos fiscais aproxima-se muito da abordagem pedagógica, de acordo com a qual agentes da lei deveriam atuar de forma prioritariamente educativa, orientando e auxiliando empresas a cumprirem a lei, como se fossem uma espécie de consultores (Bardach e Kagan, 1982; Ayres e Braithwaite, 1992; Hawkins, 2002; Braithwaite, 2005; Cunningham, Kagan e Thornton, 2003; Piore e Schrank, 2008) ${ }^{14}$.

Além disso, os resultados da análise comparativa indicaram uma forte associação entre esses dois estilos e os dois primeiros padrões de resultado descritos na seção anterior. Nos casos que resultaram em "não cumprimento da lei" ou "cumprimento da lei" (dois primeiros tipos), em geral observamos que os fiscais do trabalho implementaram ou apenas práticas coercitivas (sanções, multas, interdição etc.), ou ape- 
nas práticas pedagógicas (orientação, negociação, concessão de prazos etc. $)^{15}$.

Contudo, foi possível observar também, em mais de um terço dos casos da amostra, que os fiscais usaram uma combinação dessas duas abordagens. Surpreendentemente, nesses casos se descobriu que os fiscais conseguiram não somente que as empresas cumprissem a lei mas também as ajudaram a reduzir os custos de regularização ou a melhorar seus produtos para ocupar nichos de mercado de maior valor agregado, promovendo assim o "cumprimento sustentável da lei".

O Quadro 2 classifica alguns casos exemplares (já ou a serem mencionados) em termos dos estilos de implementação adotados. Na sequência, as subseções apresentam as evidências empíricas que dão suporte às associações entre estilo de implementação e resultados descritas anteriormente.

Quadro 2

Práticas de Fiscalização e Estilos de Implementação

Sanções

\begin{tabular}{|c|c|c|}
\hline & Sim & Não \\
\hline & 1. Estilo combinado: & 2. Estilo pedagógico: \\
\hline Sim & $\begin{array}{l}\text { Fogos de artifício (Santo Antô- } \\
\text { nio do Monte - SAM-MG); car- } \\
\text { naval (cordeiros); consórcio de } \\
\text { empregadores rurais; autopeças } \\
\text { (proteção para prensas) }\end{array}$ & $\begin{array}{l}\text { Sisal; fogos de artifício (Santo } \\
\text { Antônio de Jesus - SAJ-BA) }\end{array}$ \\
\hline & 3. Estilo punitivo/coercitivo: & 4. \\
\hline Não & $\begin{array}{l}\text { LER na Ford em Camaçari; fisca- } \\
\text { lização rural na Bahia; coopera- } \\
\text { tivas de informática em Recife }\end{array}$ & Vazio (sem intervenção) \\
\hline
\end{tabular}

Elaboração do autor.

\section{Comparações entre Casos}

As comparações entre casos sugerem que aqueles em que os fiscais usaram apenas estratégias coercitivas (célula 3) ou pedagógicas (célula 2) não evoluíram com tanto sucesso - em termos da promoção do cumprimento sustentável da lei - quanto os casos em que os fiscais combinaram sanções com assistência (célula 1).

Exemplos de casos em que os fiscais não puderam ou não quiseram empregar sanções contra empresas/produtores irregulares foram as 
intervenções na região produtora de sisal no nordeste da Bahia e nas empresas de produção de fogos de artifício de SAJ, centro-oeste da Bahia. Há muito a região do sisal é conhecida por sua alta taxa de mutilações entre os trabalhadores rurais que operam um motor de trituração primitivo (conhecido como "paraibana") que extrai a polpa da fibra do sisal. Os fiscais relutaram em empregar sanções nesse caso dada a dificuldade de se identificar claramente quem é o empregador e quem é o trabalhador em uma região habitada por pequenos produtores rurais e trabalhadores rurais pobres. Do mesmo modo, a produção de fogos de artifício em SAJ é baseada em unidades domésticas pequenas e informais, o que cria dificuldades para que os fiscais identifiquem e imponham sanções às empresas onde ocorrem explosões acidentais. Como consequência, em ambos os casos, os fiscais limitaram sua intervenção a estratégias pedagógicas (oficinas de técnicas preventivas, materiais educativos e sessões de treinamento para trabalhadores e empresários estão entre as mais comuns). Com isso, conseguiram reduções muito pequenas nas taxas de acidentes, sem promover um clima de mudança ou de melhorias significativas nas práticas empresariais e nos processos de produção.

Por sua vez, os casos nos quais os fiscais implementaram somente práticas coercitivas, sem a provisão concomitante de assistência técnica ou legal (práticas pedagógicas), também evoluíram na direção de mudanças incipientes na forma como as firmas violadoras da lei operavam. Em alguns casos, os auditores-fiscais falharam em promover qualquer melhoria em termos do cumprimento da lei por parte das empresas. Por exemplo, os fiscais do trabalho em Minas Gerais identificaram um aumento significativo da incidência de lesão por LER e de problemas de saúde mental entre os trabalhadores do setor de telemarketing na região metropolitana de Belo Horizonte. Dentre as violações das normas de segurança e saúde encontradas, destacavam-se a proibição de intervalos para repouso (os trabalhadores não podiam deixar suas estações de trabalho para ir ao banheiro fora dos poucos intervalos predeterminados) e a pressão excessiva sobre os trabalhadores para aumentar o ritmo do trabalho (com uma meta de encerrar cada ligação dentro de 30 segundos, sob pena de perder a gratificação sobre os salários). Os fiscais, nesse caso, penalizaram as empresas maiores no setor com multas pesadas, mas estas, por sua vez, deslocaram suas operações para outro estado com o objetivo de evitar a fiscalização.

Também observamos resultados semelhantes nas tentativas de outros fiscais do trabalho de lidar com a alta incidência de LER na fábrica da 
Ford em Camaçari (BA) e com os acidentes ocupacionais e o adoecimento por silicose na mineração de pedras ornamentais (mármore, granito, ardósia etc.) nos estados de Minas Gerais e Espírito Santo. Em todas essas situações, os fiscais do trabalho lançaram mão de sanções, porém não as combinaram com nenhum tipo de assistência, orientação e apoio para a adequação das empresas à lei. Assim, em geral, essas empresas preferiram pagar as multas - ou pagar um advogado que pudesse recorrer destas ao Judiciário - a investir tempo e dinheiro na mudança de seus processos produtivos.

Em outros casos nos quais os auditores-fiscais do trabalho também limitaram suas intervenções à imposição de sanções, houve melhoria nos níveis de cumprimento da lei imediatamente após a intervenção, mas tais resultados não se sustentaram ao longo do tempo, pois a maior parte dessas firmas acabou retrocedendo à irregularidade na ausência da fiscalização.

A inspeção rural no oeste da Bahia (célula 3) é mais um exemplo dos casos em que a imposição puramente coercitiva do cumprimento da lei pelos fiscais leva à redução da competitividade ou da produtividade das empresas, tendendo portanto à insustentabilidade ao longo do tempo ${ }^{16}$. Os fiscais da SRTE da Bahia projetaram um sistema de informação sofisticado (unificando as bases de dados relevantes), por meio do qual conseguem prever os picos de demanda por trabalhadores rurais na época da colheita e planejar ações de fiscalização para apanhar o maior número possível de trabalhadores e produtores informais de uma só vez. Após a identificação das áreas de maior incidência, um grupo de fiscais é designado para "pegar pesado", aplicando todas as sanções possíveis aos produtores rurais que empregam trabalhadores informais. Nessas ocasiões, os fiscais exigem que os produtores formalizem imediatamente os trabalhadores temporários e, assim, a SRTE da Bahia ganhou o título de "campeã nacional" em número de formalizações. Entretanto, como o próprio fiscal responsável admitiu, "só conseguimos isso quando monitoramos os produtores constantemente. Todo ano os mesmos produtores tornam a empregar trabalhadores informais para a safra".

De forma semelhante, nas intervenções nos polos calçadistas de Jequié (BA) e Nova Serrana (MG), fiscais do trabalho adotaram o estilo puramente coercitivo para forçar a formalização de todos os trabalhadores da indústria. Contudo, à medida que a regularização aumentou os cus- 
tos de produção, sem nenhum ganho aparente em termos de negócio, as empresas começaram a terceirizar etapas de seu processo produtivo (por exemplo, a costura de peças ou o pesponto) para antigos empregados, que passaram a trabalhar informalmente de suas residências. Em outro caso, envolvendo produção de carvão vegetal e reflorestamento, os fiscais interpretaram que as siderúrgicas da região de Camaçari (BA) eram responsáveis pelas violações trabalhistas encontradas em seus terceirizados, pois estes operavam sob contratos exclusivos com as siderúrgicas. Assim, os auditores-fiscais aplicaram sanções para forçar o fim das terceirizações e a verticalização da produção, fazendo com que as siderúrgicas absorvessem os custos da produção de carvão vegetal sem que houvesse nenhum ganho, em termos de negócio, advindo da regularização dessas siderúrgicas e de seus terceirizados.

Em suma, recorrendo às sanções, os fiscais conseguiram temporariamente afastar as empresas da informalidade, mas a falta de qualquer forma de assessoria jurídica e/ou técnica impediu o desenvolvimento de soluções mais sustentáveis para o cumprimento da lei - tais como as descritas anteriormente -, a partir das quais empresas têm incentivos para se manterem em conformidade com a legislação.

\section{Análise de Processo no Interior dos Casos}

Os contrastes entre os casos analisados indicam que a combinação entre práticas coercitivas e pedagógicas pode ter um papel significativo na explicação dos casos que resultaram em cumprimento sustentável da lei. Nesta subseção, a análise enfoca o "rastreamento de processos" no interior de quatro casos bem-sucedidos (célula 1, Quadro 2) para identificar os potenciais elos causais entre o estilo de implementação que combina práticas coercitivas e pedagógicas e o resultado "cumprimento sustentável da lei".

\section{"A sanção é o primeiro passo de um uma boa orientação"}

As intervenções no cluster de produção de fogos de artifício em SAM e na região produtora de grãos de Paracatu/Unaí (consórcio de empregadores rurais), ambas em Minas Gerais, são bons exemplos daquilo que um fiscal do trabalho me disse uma vez: "A sanção é o primeiro passo de uma boa orientação".

Em ambos os casos, os fiscais responsáveis relataram que previram condições adversas em campo e perceberam que teriam de criar um 
clima de mudança nos locais a serem fiscalizados, além de encontrar formas de comunicar que as práticas empresariais vigentes não seriam mais toleradas. Até 1998, a produção de fogos de artifício em SAM ainda era muito artesanal e pouco profissional. A procuradora do MPT envolvida com os fiscais do trabalho na intervenção em SAM relatou: "Quando chegamos lá, observamos que em quase todas as fábricas havia imagens de santos nas paredes perto dos locais mais perigosos do processo de produção. Essas eram as medidas de proteção e segurança existentes". A fiscal responsável complementou:

[Empresários e trabalhadores] estavam acostumados a uma média de seis mortes por ano. Era parte da cultura da cidade. Acreditavam que os acidentes eram lamentáveis, mas naturais. E que a produção de fogos de artifício era uma atividade necessariamente arriscada, alguém morre de vez em quando. Frequentemente compararam os riscos da atividade com as mortes no trânsito e nas estradas. Costumavam me dizer que mais pessoas morrem nas estradas do que na indústria de fogos de artifício. Nós tivemos que quebrar com essa cultura [...]. Tivemos que mostrar a eles que a taxa de acidentes era inaceitável.

A té o fim dos anos 1990, os produtores de grãos e sementes no noroeste de Minas Gerais foram poupados de inspeções por décadas, em virtude das disputas jurisdicionais internas no serviço de fiscalização (entre as SRTEs de Minas Gerais e do Distrito Federal). Na ausência de fiscalização nessa região de expansão agrícola relativamente recente, as relações trabalhistas eram tradicionalmente precárias. Quando os fiscais do trabalho chegaram, em 1998, encontraram até mesmo formas de trabalho escravo nas fazendas produtoras de grãos e sementes nos municípios de Unaí e Paracatu. Os produtores de grãos de porte médio, que representavam o poder econômico e político da região, eram abertamente contrários à formalização do trabalho rural.

Novamente, em ambos os casos (cluster de fogos de artifício e região produtora de grãos, em Minas Gerais), dadas a condição inicial de irregularidade generalizada e a fraca atuação dos sindicatos de trabalhadores locais, os fiscais: a) adotaram uma estratégia abrangente, focando todas as empresas/produtores em seu respectivo município/região; e b) "pegaram pesado" com as empresas/produtores, lançando mão de suas prerrogativas atribuídas pela CLT e aplicando rigorosamente centenas de multas sobre as empresas/produtores, além das ameaças de ações criminais contra as empresas de fogos de artifício e a desapropriação de terras dos produtores rurais para fins de reforma 
agrária. Esses choques coercitivos abrangendo todo o setor criaram uma atmosfera de incerteza e sinalizaram a necessidade de mudança, gerando discussões entre regulados e reguladores sobre o sentido de tais mudanças. Em ambos os casos, empresas/produtores rurais contestaram as ações de fiscalização, discutindo como a adoção de cada parte específica da legislação afetaria a capacidade de se manterem no mercado (exemplos nos parágrafos seguintes). Foi nesse ponto que a assistência técnica e/ou jurídica fornecida pelos fiscais teve um papel decisivo na promoção de soluções de regularização nos dois casos.

No episódio dos fogos de artifício (SAM), em consequência das interações conflituosas, os fiscais reavaliaram e flexibilizaram algumas das exigências legais, até mesmo recuando temporariamente ${ }^{17}$. Assim, conseguiram que aproximadamente $90 \%$ das empresas assinassem um Termo de Ajustamento de Conduta (TAC) junto ao MPT - inclusive as empresas líderes do cluster -, que incluía um cronograma de regularização envolvendo o cumprimento de um conjunto de normas básicas de saúde e segurança. Estas variavam de acordo com o porte da empre$\mathrm{sa}^{18}$, e o TAC instituía penalidades ainda mais severas do que as aplicadas inicialmente no caso de descumprimento. Para algumas das exigências incluídas no documento, os fiscais foram além de simplesmente oferecer um cronograma de regularização e prestaram assistência técnica direta em parceria com um engenheiro químico da Fundacentro - instituto nacional de pesquisa em saúde e segurança ocupacional vinculado ao MTE. Um exemplo da assistência foi a assessoria e a capacitação prestadas às empresas pelos fiscais e pelo engenheiro químico para a substituição do clorato de potássio - usado tradicionalmente nos explosivos fabricados por empresas em SAM, mas proibido oficialmente em muitos outros países - pelo perclorato de potássio. O fiscal do trabalho e o técnico da Fundacentro orientaram as empresas no processo de ajuste das fórmulas e das misturas antigas para tornar os fogos de artifício de SAM mais seguros, sem perder a qualidade do produto. Nas entrevistas que fizemos com empresários, todos concordaram que a substituição do clorato de potássio pelo perclorato de potássio foi uma medida-chave para reduzir o número de acidentes sem aumentar substancialmente os custos de fabricação.

Da mesma forma, no caso da produção de sementes e grãos em Paracatu e em Unaí, as interações igualmente conflituosas entre regulados e reguladores sensibilizaram os fiscais, que entenderam que formas alternativas de empregar formalmente trabalhadores rurais temporá- 
rios eram necessárias porque, de fato, a legislação vigente impunha encargos financeiros e burocráticos excessivamente pesados aos produtores. Os fiscais de Minas Gerais tinham ouvido de seus colegas nos estados de São Paulo e Paraná, bem como dos promotores do MPT, relatos sobre tentativas malsucedidas de formalizar consórcios de empregadores rurais. Em 1999, planejaram uma visita técnica a Rolândia, Paraná, onde um grupo de produtores de cana-de-açúcar travava uma batalha judicial para validar seu arranjo empregatício. Os fiscais perceberam que podiam adaptar e melhorar essa experiência para remediar a situação que estavam enfrentando no noroeste de Minas Gerais, e buscaram apoio técnico e assessoria jurídica dos promotores do MPT e de dois advogados trabalhistas do Paraná, que os ajudaram a transformar o consórcio em um instrumento jurídico (um acordo formal entre produtores) que: a) respeita os princípios básicos do código trabalhista e outras leis que regulam o emprego rural; b) garante as proteções e os benefícios exigidos para os trabalhadores (por exemplo, aposentadoria, seguro-desemprego etc.); e c) reduz os encargos da formalização para cada produtor individual, pois os membros do consórcio passaram a compartilhar os custos administrativos e financeiros de empregar trabalhadores formalmente (como descrito na seção Implementação da Legislação Trabalhista no Brasil: Compreendendo a Variação nos Resultados, p. 739). De acordo com um fiscal, “[...] nós os castigamos com multas, mas também oferecemos os consórcios como uma alternativa para atender os dispositivos essenciais da legislação trabalhista. Mostramos a eles que a adoção do consórcio seria uma maneira mais barata de cumprir a lei"19.

Após a criação de vários consórcios na área de Paracatu/Unaí, os fiscais realizaram oficinas de sensibilização e de capacitação em dez capitais e elaboraram um manual detalhando passo a passo como os produtores rurais poderiam implementar consórcios em suas áreas.

"Por que devo ouvir suas recomendações? É assim que conduzo meus negócios desde $[\ldots]^{\prime \prime}$

Diferentemente das duas experiências analisadas anteriormente, a sequência de intervenções foi exatamente o inverso do ocorrido no caso dos cordeiros do carnaval - trabalhadores que seguram as cordas dos blocos - e da indústria de autopeças (proteção de prensas), respectivamente na Bahia e em Minas Gerais. A intervenção nesses casos começou com estratégias pedagógicas - as quais foram incentivadas por 
meio de instruções normativas a partir de 1998 -, mas só produziu impactos significativos mais tarde, quando os fiscais combinaram os esforços em andamento com sanções rigorosas.

No caso do carnaval, os fiscais tentaram inicialmente discutir, com as três associações de blocos de trio em Salvador, a questão da formalização dos cordeiros, enviando uma notificação na qual os blocos e as empresas subcontratadas eram convidados para uma reunião e solicitando as listas de trabalhadores a serem empregados para o carnaval de 2003. Como os blocos de trio de Salvador sempre empregaram os cordeiros informal e precariamente, as associações não tinham interesse em mudar a situação e não atenderam à notificação dos fiscais. Em resposta, a SRTE da Bahia enviou quarenta fiscais para verificar as condições de trabalho durante a festa de rua. Os fiscais aplicaram multas para cada irregularidade encontrada nos blocos de trio (chegando a aproximadamente $\mathrm{R} \$ 200$ mil no caso do maior bloco de Salvador, em um total de 400 multas, em virtude da falta de registro formal nas carteiras de trabalho dos cordeiros).

Somente assim os blocos responderam por meio de suas associações, resistindo e contestando as ações de fiscalização ${ }^{20}$. Argumentaram que a formalização de centenas de cordeiros por alguns dias era administrativa e financeiramente impossível. Por sua vez, os próprios cordeiros estavam relutantes em relação à formalização de seus empregos. De acordo com o vice-presidente do sindicato dos cordeiros criado recentemente,

muitos de nós não querem ter um contrato formal registrado na carteira. Muitos cordeiros sequer têm carteira de trabalho e os documentos necessários para iniciar o processo de registro na carteira. A maioria das pessoas não quer ser discriminada tendo a palavra "cordeiro" escrita na carteira e por ter sido contratado e despedido em poucos dias.

Em resposta, a SRTE criou um grupo de estudos constituído de fiscais para analisar e estudar possibilidades de resolver o conflito, porque, como um fiscal comentou, "[nós] não sabíamos como aplicar a lei nesse caso específico, envolvendo uma forma tão atípica de emprego". Após uma série de reuniões realizadas ao longo de três meses entre o grupo de fiscais e as associações de blocos de trio, os fiscais decidiram ceder na exigência da carteira de trabalho contanto que todos os blocos assinassem um acordo coletivo para um novo arranjo empregatício. No lugar da exigência da carteira, os fiscais admitiram, no acordo coletivo, a 
possibilidade de classificar os cordeiros como "prestadores de serviço individuais" (em vez de trabalhadores diretos), permitindo assim que assinassem contratos de serviço com os blocos ou suas respectivas empresas subcontratadas ${ }^{21}$. $\mathrm{O}$ acordo coletivo ${ }^{22}$, firmado por 178 blocos comerciais e blocos sem fins lucrativos, com disposições diferentes para cada tipo de organização, especifica o conteúdo do contrato de serviço e inclui um modelo desse contrato, composto de cláusulas relacionadas às condições de trabalho, como um valor fixo de diária de trabalho, condições de saúde e segurança (luvas, proteção auricular, protetor solar etc.), e um seguro pago pelo empregador para cobertura de acidentes e atenção à saúde ${ }^{23}$. Após a assinatura do acordo, os fiscais, em colaboração com a Secretaria de Saúde de Salvador, distribuíram um panfleto informando os direitos trabalhistas dos cordeiros e o conteúdo do acordo coletivo.

De forma semelhante, no caso da indústria de autopeças, além de uma tentativa fracassada de mediar um acordo de negociação coletiva entre o sindicato dos metalúrgicos e a Federação das Indústrias do Estado de Minas Gerais (Fiemg) para a proteção de prensas e outras máquinas, em 1999-200024, os fiscais começaram investindo na prestação de orientação técnica às empresas, a fim de melhorar o índice de conformidade com a legislação. Em 2001, formaram um grupo de nove fiscais, um procurador do MPT e pesquisadores da Fundacentro, visando superar a falta de conhecimento técnico sobre o funcionamento das máquinas e padronizar os procedimentos de fiscalização para evitar inconsistências (que poderiam ser usadas na justiça contra eles). De acordo com um dos fiscais da equipe,

costumávamos realizar reuniões regulares durante toda a operação para discutir práticas de inspeção e acumular conhecimento técnico com as experiências uns dos outros. Nossa equipe também atuou como grupo de estudo, e pesquisamos o funcionamento das máquinas, os catálogos dos fornecedores de equipamentos protetores, tudo para conhecer as melhores alternativas de controle da perda de produtividade e todo o material escrito disponível sobre as experiências de colegas fiscais em outros estados, como São Paulo e Rio Grande do Sul.

Como resultado, convidaram um grupo de 120 empresas de autopeças (o grupo-alvo) para um evento de formação na Fundacentro, no qual as empresas receberam uma notificação coletiva e instruções técnicas detalhadas sobre o que deveriam fazer para regularizar a situação de suas máquinas (chegando a descrever os equipamentos específicos ne- 
cessários e como instalá-los). Contudo, mesmo tendo fornecido instruções e assistência técnica às empresas, os fiscais descobriram, alguns meses mais tarde, que $98 \%$ das empresas do grupo-alvo ainda tinham máquinas desprotegidas, e o índice de acidentes ainda era muito alto (uma média de dois acidentes por mês, envolvendo mutilação, na área metropolitana de Belo Horizonte). Em resposta, os fiscais interditaram a operação de todas as prensas e equipamentos similares sem proteção. Até 2005, 400 prensas ou equipamentos similares foram interditados em 59 empresas ( $50 \%$ do grupo-alvo). Algumas empresas tiveram $100 \%$ de suas máquinas interditadas. Além de proibir a operação das máquinas, os fiscais também coletaram mais provas e documentação para uso dos procuradores do MPT e para os parentes das vítimas dos acidentes em processos penais contra as empresas. Como resultado do rigor dos fiscais, as empresas adequaram suas máquinas e conseguiram a liberação de aproximadamente $70 \%$ das prensas interditadas. Em alguns casos, as máquinas foram adaptadas em menos de uma semana. O fiscal responsável pela intervenção comentou:

Foi preciso muita pressão para fazer com que as empresas mudassem suas práticas [...] proibindo a operação das máquinas, o que causou um grande problema para os fornecedores, que tinham contratos a cumprir com a Fiat. A medida finalmente chamou a atenção das empresas para a necessidade de mudança. As notificações e orientações anteriores não haviam surtido efeito ${ }^{25}$.

\section{Um Elo Causal?}

A análise comparativa desenvolvida neste artigo visou explicar a variação nos resultados da política de inspeção do trabalho no Brasil e identificar os possíveis elos causais entre os resultados observados e os estilos de implementação adotados pelos auditores-fiscais do trabalho. Quando observamos o conjunto dos casos que integram a amostra investigada nesta pesquisa (Quadro 3), podemos perceber a alta correspondência entre os padrões de resultados observados (apresentados no Quadro 1) e os estilos de implementação (descritos anteriormente e no Quadro 2). Essa alta correspondência entre os resultados e as hipóteses explicativas provém de uma explicação consistente do impacto de estilos de implementação sobre a variação nos resultados de políticas públicas.

A amostra, composta de 24 casos (Quadro 3), não foi construída com o objetivo de ser representativa de todos os casos trabalhados pelos fis- 
cais do trabalho no Brasil. Mais precisamente, o objetivo dessa amostra é capturar uma ampla variação de contextos e de situações para testar o argumento causal proposto sob condições as mais adversas possíveis. A partir dessa amostra, foram selecionados quatro casos de cumprimento sustentável da lei para uma análise aprofundada. Entretanto, esses não são os únicos casos ilustrativos da associação entre a combinação de práticas coercitivas e pedagógicas e os resultados de cumprimento sustentável da lei. Ao longo da pesquisa de campo, identificamos tais resultados em setores tão distintos quanto o petroquímico (Camaçari-BA), o de galvânicas (ABC-SP), assim como na erradicação de formas contemporâneas de trabalho escravo nas áreas rurais do norte e do nordeste do país (sobretudo no Pará). Nas indústrias petroquímica e de galvanização, baixos níveis de cumprimento das normas de segurança e de saúde no trabalho coexistiam com taxas relativamente altas de adoecimento ocupacional (incluindo câncer), em virtude da exposição dos trabalhadores a derivados de benzeno e zinco. Nesses dois casos, fiscais do trabalho empregaram seu poder coercitivo (autuando as empresas e acionando outros órgãos de fiscalização, como o Ministério Público) e trabalharam com as empresas de maior porte no desenvolvimento de um sistema tripartite de monitoramento do manuseio de produtos químicos por seus fornecedores e terceirizados. O caso do trabalho escravo é outro exemplo no qual houve combinação de sanções pesadas contra produtores rurais com outras estratégias, tais como a criação de uma lista suja - que publiciza os empregadores envolvidos com trabalho escravo - utilizada por instituições financeiras públicas e privadas para negar financiamento a produtores rurais violadores da lei.

Em outro caso da amostra, os auditores-fiscais também empregaram uma combinação de sanção com assistência, mas falharam na produção do cumprimento sustentável da lei. Ainda que a intervenção desses agentes - por exemplo, com vistas a melhorar as condições de segurança na indústria da construção civil em Belo Horizonte - incluísse multas, negociação e treinamento, as empresas possuíam incentivos para evitar a regularização e reduzir seus custos de produção. Da mesma forma, existem também casos nos quais os fiscais empregaram apenas sanções ou apenas práticas pedagógicas e que resultaram no cumprimento sustentável da lei. Esses casos incluem as convenções coletivas mediadas pelos fiscais do trabalho no setor metal-mecânico no $\mathrm{ABC}(\mathrm{SP})$ e na indústria de celulose e de papel no sul da Bahia, além da "primeirização" em uma operação da Vale em Itabira, uma vez que a 
Roberto Rocha C. Pires

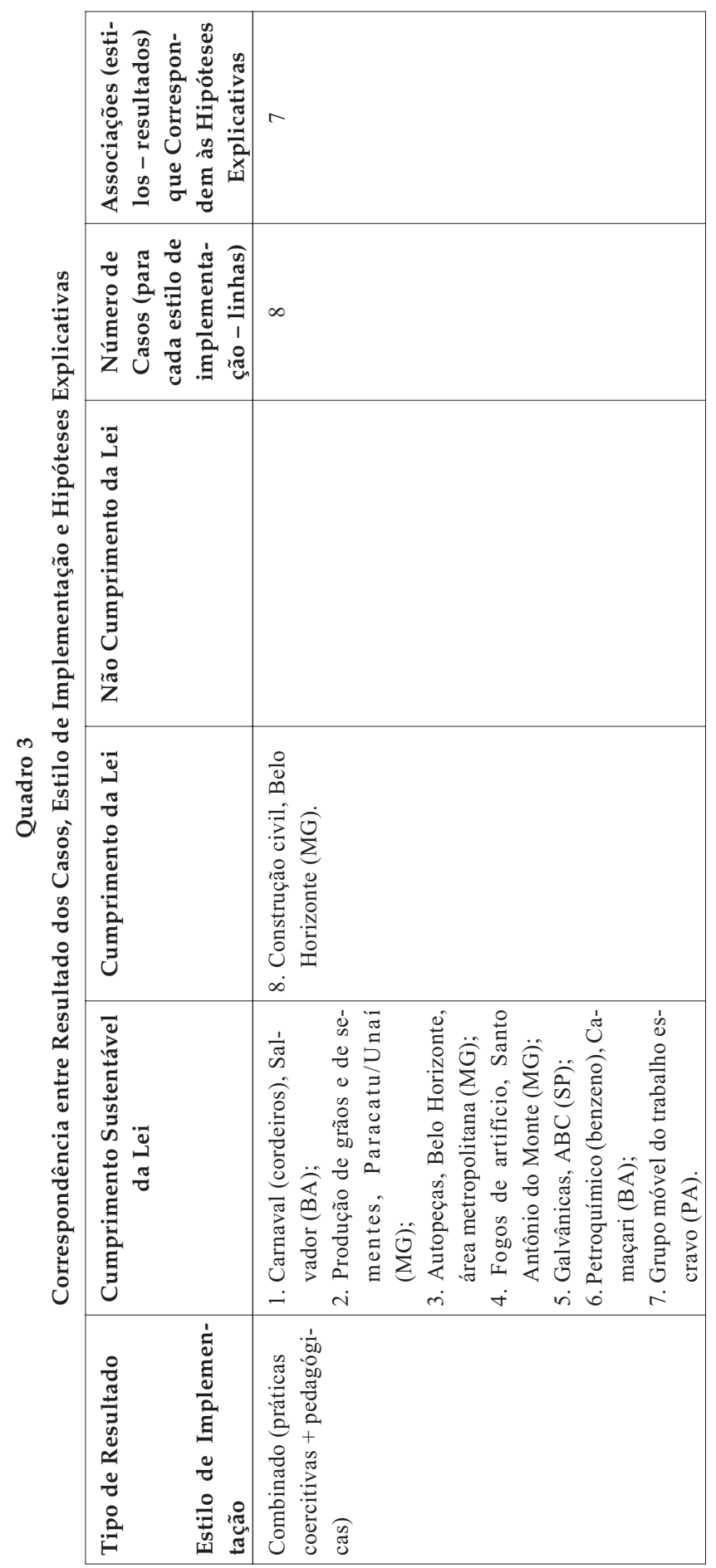


Estilos de Implementação e Resultados de Políticas Públicas...

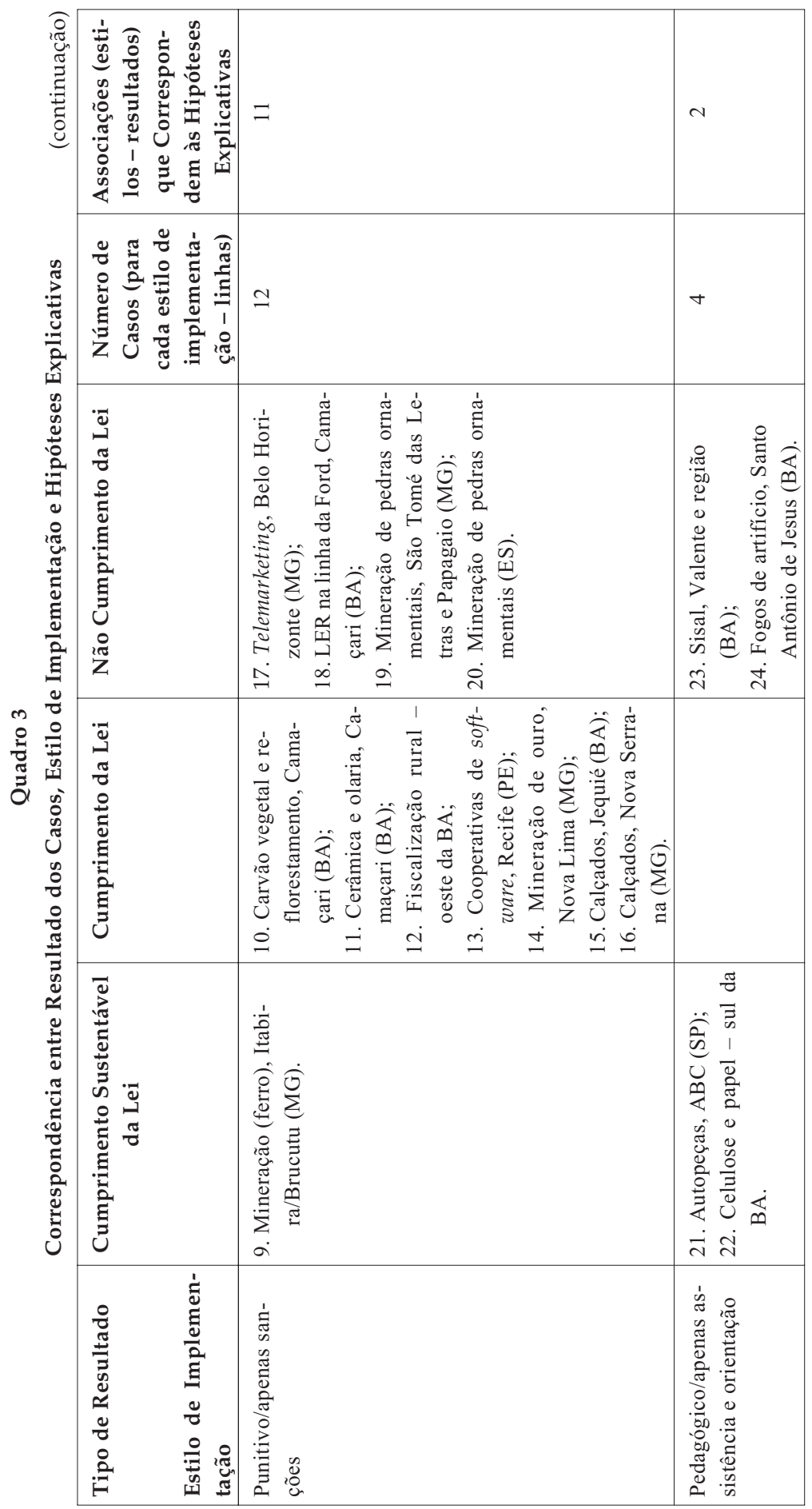


empresa percebeu, a partir das ações coercitivas dos fiscais, as vantagens em termos de redução de custo da contratação direta de mineradores.

O fato de que esses casos não confirmam a associação entre estilos de implementação e resultados de política sugere apenas que o argumento aqui desenvolvido não é determinístico, mas sim probabilístico isto é, a adoção de um estilo de implementação que combina sanções e orientação aumenta a propensão da incidência de resultados como o cumprimento sustentável da lei (Quadro 3). A margem de erro sugerida pelos casos desviantes anteriormente descritos serve apenas como um lembrete de que muitas outras variáveis não examinadas neste estudo - por exemplo, o nível de organização de associações empresariais e sindicatos de trabalhadores, ciclos econômicos locais, pressões de compradores ou fornecedores domésticos e estrangeiros, entre outras - podem interferir criando novas oportunidades e constrangimentos, tanto para as empresas quanto para os fiscais buscarem a promoção do cumprimento sustentável da lei. Entretanto, a contribuição do presente argumento - que sugere uma forte (porém não determinista) associação entre combinação de práticas e resultados sustentáveis reside em sua capacidade de demonstrar empiricamente a importância da variável "estilos de implementação" para a compreensão da variação nos resultados de políticas públicas.

\section{CONCLUSÃO}

Neste estudo, chamamos a atenção para a implementação como variável importante, mas frequentemente negligenciada, para a explicação da variação nos resultados de políticas públicas. Mais especificamente, o presente argumento desagrega burocracias implementadoras ao tomar como base uma literatura que reconhece o papel do indivíduo na burocracia; ao sistematizar possíveis idiossincrasias (decisões, práticas e comportamentos de agentes burocráticos) em variedades de estilos de implementação; e, finalmente, ao avaliar os impactos desses estilos sobre os resultados de políticas públicas.

Quando aplicado ao caso da política de inspeção do trabalho, responsável pela implementação da legislação trabalhista no Brasil, o presente estudo apresentou uma perspectiva analítica alternativa capaz de gerar novas interpretações e entendimentos sobre um tema altamente polêmico, caracterizado por um debate ideologicamente polarizado e 
impasse político. Por um lado, a literatura econômica mainstream e atores como organismos internacionais e associações empresariais domésticas frequentemente descrevem a legislação trabalhista brasileira como anacrônica, obsoleta e geradora de ineficiências econômicas ${ }^{26}$ (podendo acumular encargos trabalhistas de até 103\% sobre salários); e, consequentemente, propõem a desregulamentação e a flexibilização do mercado de trabalho. Por outro lado, atores como entidades sindicais e seus órgãos de assessoria (como o Dieese - Departamento Intersindical de Estatísticas e Estudos Socioeconômicos), movimentos internacionais e alguns partidos políticos defendem a manutenção das proteções e dos direitos sociais como conquistas históricas essenciais para o bem-estar do cidadão. Alguns estudos nessa linha têm desafiado metodologias existentes no cálculo dos encargos trabalhistas ${ }^{27}$ e demonstrado que direitos trabalhistas e proteção ao emprego no Brasil não são obstáculos à inovação e à competitividade internacional (Noronha, De Negri e Artur, 2006). Assim, como resultado desse debate envolvendo posições extremas, observa-se, desde a promulgação da Constituição de 1988, um impasse político que impede a realização de reformas e a percepção de alternativas para conciliar desenvolvimento econômico e social no Brasil.

Nesse sentido, a perspectiva analítica que enfoca a atuação dos fiscais do trabalho e seus estilos de implementação oferece uma alternativa ao atual debate, ao demonstrar que no cotidiano da implementação da lei existe uma margem de manobra mais ampla do que as discussões correntes poderiam antecipar. Desse modo, a identificação de diferentes estilos de implementação, como possibilidades empíricas para a atuação dos fiscais do trabalho, contribui para a compreensão de por que em algumas situações observamos resultados positivos e em outros episódios nos deparamos com fracassos na aplicação da legislação trabalhista no Brasil.

Em suma, os resultados deste estudo sugerem que a incorporação da variável estilos de implementação se faz necessária ao desenvolvimento de uma compreensão mais refinada sobre a atuação de burocracias governamentais e ao avanço do debate sobre políticas públicas, seus aprimoramentos e resultados.

(Recebido para publicação em novembro de 2008) (Versão definitiva em julho de 2009) 


\section{Roberto Rocha C. Pires}

\section{NOTAS}

1. A percepção de que funcionários de linha de frente possuem discricionariedade na condução de suas tarefas laborais cotidianas já era corrente em estudos anteriores sobre corporações policiais ou agentes do Judiciário desde os anos 1960 e 1970 (ver Davis, 1969; Wilson, 1968; Van Maanen, 1973; e Bittner, 1967).

2. Burocracias de linha de frente (street-level bureaucracies) são caracterizadas pela insuficiência de recursos diante de demandas abundantes em um contexto de objetivos ambíguos. Seus funcionários frequentemente lidam com "clientes" não voluntários (beneficiários de programas) e trabalham "em campo", distantes de seus supervisores, em situações complexas e não reduzíveis a objetivos programáticos. O argumento principal de Lipsky (1980) é que, sob essas condições, burocratas de linha de frente "definem" as políticas, que originalmente eles eram responsáveis por implementar, à medida que lidam com as circunstâncias, pressões e incertezas envolvidas em seu trabalho.

3. Olivro Administrative Behavior, de Herbert Simon (1947), já continha um insight semelhante: "A tarefa concreta de realização dos objetivos de uma organização recai sobre as pessoas que operam nos níveis mais baixos da hierarquia administrativa. [...] No estudo de organizações, o funcionário de nível operacional deve ser o foco de atenção, pois o sucesso da estrutura será julgado com base em seu desempenho dentro dela. Uma melhor compreensão sobre a estrutura e o funcionamento de uma organização pode ser obtida por meio da análise da maneira pela qual as decisões e os comportamentos de tais funcionários são influenciados no âmbito de e pela organização" (ibidem:1-2; tradução do autor).

4. Este estudo está centrado na análise do impacto da variação de estilos de implementação sobre os resultados de políticas. Não se inscreve no escopo deste artigo uma análise do processo por meio do qual burocratas de linha de frente desenvolvem ou aderem a estilos de implementação. A literatura existente oferece algumas explicações, ainda que incompletas, sobre a origem dos estilos. Por exemplo, para Lipsky (1980), diferentes estilos derivam de uma percepção racional-estratégica por parte do burocrata para ganhar controle sobre seu trabalho/público; para Maynard-Moody e Musheno (2003), estilos derivam da participação em comunidades e do compartilhamento de valores, normas, símbolos etc., entre outros argumentos.

5. Uma análise mais detida da atuação do MPT e da Justiça do Trabalho foge ao escopo do presente estudo. Análises sobre esse órgãos podem ser encontradas em Cardoso e Lage (2007) e Artur (2007).

6. Em Cardoso e Lage $(2005 ; 2007)$, encontram-se estudos de referência sobre regulação, justiça e inspeção do trabalho no Brasil. Os autores descrevem mais detalhadamente a estrutura organizacional da inspeção do trabalho e sua evolução histórica. De forma semelhante à abordagem desenvolvida neste artigo, Cardoso e Lage enfatizam a necessidade da observação empírica de como se dá o cumprimento da lei e sua efetividade para além de sua normatividade ("lei escrita").

7. Dada a dimensão da tarefa, o número de fiscais no Brasil é $50 \%$ menor do que o recomendado pela Organização Internacional do Trabalho (OIT), e o índice por 100 mil trabalhadores no Brasil está abaixo dos índices apresentados por outros países da América do Sul, como Argentina, Uruguai e Chile (Piore e Schrank, 2008). 
8. A seleção dos casos em três estados - Minas Gerais, Bahia e Pernambuco - visa garantir variação em termos de contextos e níveis de desenvolvimento social e econômico. Por um lado, dois estados (Minas Gerais e Bahia) estão entre os lugares menos propensos à implementação de estratégias de desenvolvimento favoráveis aos trabalhadores. Ambos os estados têm uma longa tradição de política industrial baseada na atração de investimentos por meio de incentivos fiscais (mais agressivamente na Bahia), setor público relativamente forte e baixa oposição política (continuidade dos partidos de centro-direita no governo estadual nas últimas duas décadas, exceto na Bahia em 2007). Já em Pernambuco, uma política industrial relativamente menos agressiva coexiste com um forte movimento sindical e organização patronal no campo e alta contestabilidade e alternação no poder entre elites políticas (DFID, 2007). Além disso, existem outras diferenças importantes entre os três estados. Minas Gerais tem um desempenho significativamente melhor do que Bahia e Pernambuco no que se refere à maioria dos indicadores sociais - como Índice de Desenvolvimento Humano (IDH), taxa de analfabetismo, índice de mortalidade, entre outros - e à maioria dos indicadores econômicos (como distribuição de renda, índice de Gini, PIB). Além disso, estudos anteriores (Avritzer, 2007) demonstraram que a sociedade civil (incluindo os sindicatos de trabalhadores) é significativamente mais organizada e atuante em Minas Gerais e em Pernambuco do que na Bahia.

9. Para mais detalhes sobre esses dois casos, assim como outros casos que resultaram no cumprimento sustentável da lei, ver Pires (2008a; 2008b).

10. A legislação sobre salários e jornada de trabalho no Brasil, instituída em 1943, sobretudo com base nas características típicas do emprego na indústria (por exemplo, relacionamentos de longo prazo), é universal, aplicável a trabalhadores e a empregadores em todos os setores da economia.

11. Algumas partes desta seção se baseiam em artigo de minha autoria publicado pelo Instituto de Pesquisa Econômica Aplicada (Ipea) em agosto de 2008 (Pires, 2008a).

12. Rastreamento (ou análise) de processos no interior de casos envolve a exploração de evidências sobre processos causais e mecanismos que associem a variável independente à variável dependente em busca dos elos específicos por meio dos quais a primeira (por exemplo, estilos de inspeção) se conecta com a segunda (por exemplo, resultados de políticas públicas). Diferentemente da técnica de comparação entre casos (cross-case), o rastreamento de processos emprega ferramentas para inferência causal (com base nas evidências colhidas em entrevistas, documentos etc. que explicitam o link entre as variáveis dependente e independente) que não dependem da análise do relacionamento entre variáveis na comparação entre casos. A análise de processos no interior de casos (within-case) permite que a investigação vá além das inferências a respeito da probabilidade de que a hipótese testada seja encontrada em amostras mais amplas (ou na "população"), facilitando, por sua vez, a identificação de como e em que medida a hipótese explicativa causou os resultados observados em cada caso. Para uma discussão mais detalhada a respeito dessas técnicas metodológicas, ver Brady e Collier (2004) e George e Bennet (2004).

13. De acordo com o modelo repressivo, o cumprimento das normas é o resultado de uma análise de custo-benefício na qual as empresas desistem de violar a lei quando a probabilidade de ser pego (fiscalização) e o custo da punição (multas) são mais altos do que os benefícios do descumprimento da lei. Assim, sob esse modelo, espera-se que os fiscais encontrem todo tipo possível de irregularidade e apliquem as respecti- 


\section{Roberto Rocha C. Pires}

vas sanções para cada uma delas quando inspecionam os locais de trabalho. Estudos anteriores sobre a inspeção do trabalho no Brasil enfatizaram tal perspectiva (Cardoso e Lage, 2007).

14. De acordo com os proponentes da abordagem pedagógica, a aplicação rigorosa da lei, baseada em relacionamentos de oposição e punição entre reguladores e regulados, leva à falta de razoabilidade e cria desincentivos para a regularização. Nesse caso, espera-se que os fiscais priorizem a persuasão e a orientação em vez de meios coercitivos de fiscalização (Piore e Schrank, 2006).

15. Ambos os estilos, "punitivo" e "pedagógico", têm respaldo nas leis e nas normas que regulamentam a atuação dos fiscais do trabalho no Brasil. A promulgação da CLT, em 1943, pelo presidente Vargas, conferiu aos fiscais do trabalho a competência de zelar pela aplicação de suas disposições e concedeu-lhes o poder de intervir em empresas privadas e penalizá-las por infrações cometidas. Posteriormente, o Regulamento da Inspeção do Trabalho (RIT), promulgado em 1965 e revisado em 2002, institui que para cada infração identificada durante uma inspeção caberá a respectiva autuação, tal como estipulado em lei. Entre 1994-2002, durante a gestão de Fernando Henrique Cardoso, diversas tentativas de flexibilização da legislação trabalhista fracassaram, mas algumas mudanças na gestão da inspeção do trabalho foram introduzidas por meio de portarias ministeriais e de instruções normativas, como as "mesas de entendimento", que possibilitam ao fiscal mediar conflitos entre trabalhadores e empregadores e firmar "termos de compromisso" entre as partes. Uma discussão detalhada e histórica sobre o porquê e sob que condições os fiscais do trabalho escolhem entre os estilos de implementação definidos anteriormente será objeto de estudo de um artigo subsequente.

16. Outro exemplo já mencionado (Quadro 2) é o das cooperativas no setor de informática em Recife (PE).

17. Os exemplos de exigências reavaliadas pelos reguladores e mencionados pelos empresários incluíam: placas indicando rotas de evacuação no caso de explosão ("quando tem uma explosão, é como o estouro da boiada, ninguém vê as placas", disse um empresário); botas antiestáticas específicas, não disponíveis no mercado doméstico; lavagem dos uniformes dos empregados diariamente pela própria empresa; entre outros.

18. Em geral, os fiscais do trabalho concederam prazos mais longos para as empresas menores, e todas as empresas se beneficiaram de prorrogações nos prazos para as exigências técnicas mais complexas (por exemplo, construção de novas instalações, laboratório de testes etc.).

19. Minas Gerais é o estado com o maior número de consórcios rurais implementados no Brasil desde a década de 1990. Também é o estado com o maior número de multas emitidas durante a fiscalização nas áreas rurais. Em 2005, os fiscais de Minas Gerais emitiram quase três vezes mais multas do que seus colegas em São Paulo, Mato Grosso, Maranhão, Pará, Goiás e Tocantins, e seis vezes mais do que os fiscais da Bahia, sendo todos estados com setores agrícolas de grande porte.

20. Muitas empresas contestaram as multas judicialmente. No início de 2007, o Tribunal de Justiça do Trabalho da Bahia decidiu manter as multas, legitimando a ação dos fiscais. 
21. A interpretação atual da Justiça do Trabalho no Brasil proíbe a subcontratação de atividades-fim (ao contrário das atividades auxiliares/administrativas, nas quais a subcontratação é permitida). Contudo, os fiscais do trabalho entenderam, nesse caso, que, como não há relação pessoal entre os administradores dos blocos e os cordeiros, estes podem ser considerados prestadores de serviço em vez de trabalhadores regulares.

22. O acordo coletivo é assinado todo ano para permitir novas negociações - aumento da diária, por exemplo-, e os fiscais monitoram o cumprimento dos termos do acordo. Em 2007, os fiscais recorreram a procuradores do Ministério Público do Trabalho para a operação, aumentando o poder de sanção (valor das multas) ao transformar o acordo coletivo em TAC.

23. O seguro foi incluído no contrato como forma de compensar as dificuldades administrativas de se pagar a contribuição previdenciária exigida para cada trabalhador (muitos cordeiros na época não tinham inscrição na previdência). Assim, quando não era possível pagar a contribuição previdenciária, os blocos ou as empresas subcontratadas adquiriam seguro para cada cordeiro a fim de cobrir acidentes individuais ou atendimento à saúde.

24. Para alguns entrevistados, o acordo de negociação coletiva fracassou porque os sindicatos dos trabalhadores queriam incluir demandas além da proteção das máquinas, como estabilidade no emprego e comitês de chão de fábrica. Para outros, o acordo não se materializou porque a Fiemg fez tudo para atrasar a assinatura e exigiu um tempo muito longo para seu pleno cumprimento (proteção para todas as máquinas).

25. Os fiscais ainda estão acompanhando as empresas para melhorar a questão da produtividade. Promoveram um seminário sobre proteção de prensas e equipamentos similares em 2003; e mais tarde, no mesmo ano, uma audiência pública na Comissão de Trabalho da Assembleia Legislativa do estado para discutir o problema e promover a conscientização sobre a necessidade de melhorar as condições de trabalho no setor de autopeças. Também em consequência desse processo, ainda em andamento, nos últimos cinco anos surgiu um mercado de consultoria e de assistência técnica. Essas empresas têm ajudado os produtores de autopeças a enfrentar o desafio de melhorar a produtividade e, ao mesmo tempo, a investir na segurança das máquinas (por meio de capacitação, desenho de projetos de proteção, ergonomia, equipamentos de proteção mais modernos, manutenção etc.).

26. A pesquisa World Business Environment Survey, do Banco Mundial (Batra, Kaufmann e Stone, 2003), identifica a regulação do mercado de trabalho como um dos principais obstáculos para a construção de condições propícias para o funcionamento e o crescimento das empresas. Esse e outros estudos argumentam que a ampliação de direitos trabalhistas e proteções ao emprego estão associados às causas da ineficiência das empresas, ao crescimento das taxas de desemprego e à expansão do setor informal.

27. Ver Cardoso e Lage (2007) e Noronha e Artur (2006) para uma discussão sobre diferentes metodologias para o cálculo dos encargos trabalhistas (que variam de $36 \%$ a $103 \%$ sobre salários). 


\section{REFERÊNCIAS BIBLIOGRÁFICAS}

ALLISON, Graham. (1969), "Conceptual Models and the Cuban Missile Crisis". American Political Science Review, vol. 63, no 3, pp. 689-718.

ARTUR, Karen. (2007), O TST frente à Terceirização. São Carlos, EdUFSCar.

AVRITZER, Leonardo (org.). (2007), A Participação Social no Nordeste. Belo Horizonte, Ed. UFMG.

AYRES, Ian e BRAITHWAITE, John. (1992), Responsive Regulation: Transcending the Deregulation Debate. Oxford, Oxford University Press.

BARDACH, Eugene. (1977), The Implementation Game. Cambridge, MIT Press.

e KAGAN, Robert. (1982), Going by the Book: The Problem of Regulatory Unreasonableness. Philadelphia, Temple University Press.

BATRA, Geeta, KAUFMANN, Daniel e STONE, Andrew H. W. (2003), Investment Climate around the World: Voices of the Firms from the World Business Environment Survey. Washington, D.C., World Bank.

BAUMECKER, Ione e FARIA, Mário Parreiras de. (2006), "Private and State Interventions in Safety and Health at Work". OSH \& Development, vol. 8, pp. 9-21.

BECKER, Gary. (1968), “Crime and Punishment: An Economic Analysis”. Journal of Political Economy, vol. 76, pp. 169-217.

BIANCHI, Tito. (2002), Redistribution within a Democratic Society: The "Finished Business" of the Italian Agrarian Reform. Tese de doutorado, Departamento de Estudos Urbanos e Planejamento, Massachusetts Institute of Technology.

BID-IPES (Banco Interamericano de Desenvolvimento-Informe de Progreso Económico y Social). (2006), La Política de las Políticas Públicas: Progreso Económico y Social en América Latina. Washington, D.C., BID.

BITTNER, Egon. (1967), “The Police on Skid Row: A Study of Peace Keeping”. American Sociological Review, vol. 32, no 5, pp. 699-715.

BRADY, Henry e COLLIER, David. (2004), Rethink Social Inquiry: Diverse Tools, Shared Standards. London, Rowman \& Littlefield Publishers.

BRAITHWAITE, John. (2005), "Responsive Regulation and Developing Economies". World Development, vol. 34, no 5, pp. 884-898.

CARDOSO, Adalberto e LAGE, Telma. (2005), "A Inspeção do Trabalho no Brasil”. DADOS, vol. 48, no 3, pp. 451-490.

. (2007), As Normas e os Fatos: Desenho e Efetividade das Instituições de Regulação do Mercado de Trabalho no Brasil. Rio de Janeiro, Editora FGV.

CROOK, Richard e AYEE, Joseph. (2006), “Urban Service Partnerships, 'Street-Level Bureaucrats' and Environmental Sanitation in Mumasi and Accra, Ghana: Coping with Organisational Change in the Public Bureaucracy". Development Policy Review, vol. 23, no 1 , pp. 1-23.

CUNNINGHAM, Neil, KAGAN, Robert e THORNTON, Dorothy. (2003), Shades of Green: Business, Regulation, and Environment. Stanford, Stanford University Press. 
DAVIS, Kenneth C. (1969), Discretionary Justice. Baton Rouge, Louisiana State University Press.

DFID (Department for International Development). (2007), A Political Economy Analysis of Public Sector Management in the Brazilian States. Relatório de pesquisa. Brasília.

EHRLICH, Isaac. (1972), "The Deterrent Effect of Criminal Law Enforcement". The Journal of Legal Studies, vol. 1, no 2, pp. 259-276.

GEORGE, Alexander e BENNET, Andrew. (2004), Case Studies and Theory Development in the Social Sciences. Cambridge, MIT Press.

GRINDLE, Merilee e THOMAS, John. (1989), "Policy Makers, Policy Choices, and Policy Outcomes: The Political Economy of Reform in Developing Countries". Policy Sciences, vol. 22, pp. 213-248.

HAWKINS, Keith. (1992), The Uses of Discretion. Oxford, Oxford University Press.

(2002), Law as Last Resort: Prosecution Decision-Making in a Regulating Agency. Oxford, Oxford University Press.

IBGE (Instituto Brasileiro de Geografia e Estatística). (2005), Pesquisa Nacional por Amostra de Domicílios - PNAD. Diretoria de Pesquisas, Coordenação de Trabalho e Rendimento. Rio de Janeiro, IBGE.

JOSHI, Anuradha. (2000), Roots of Change: Front Line Workers and Forest Policy Reform in West Bengal. Tese de doutorado, Departamento de Estudos Urbanos e Planejamento, Massachusetts Institute of Technology.

JUSTICE, Judith. (1986), Policies, Plans \& People: Culture and Health Development in Nepal. Berkeley, University of California Press, pp. 101-106.

LIPSKY, Michael. (1980), Street-Level Bureaucracy, Dilemmas of the Individual in Public Services. New York, Russell Sage Foundation.

MAYNARD-MOODY, Steven e MUSHENO, Michael. (2003), Cops, Teachers, and Counselors: Stories from the Front Lines of Public Service. Ann Arbor, University of Michigan Press.

MIGUEL, Antônia. (2004), A Inspeção do Trabalho no Governo FHC: Análise sobre a Política de Fiscalização do Trabalho. Dissertação de mestrado, Programa de Pós-Graduação em Ciências Sociais, Universidade Federal de São Carlos, São Carlos, SP.

NAKAMURA, Robert e SMALLWOOD, Frank. (1980), The Politics of Policy Implementation. New York, St. Martin's Press.

NORONHA, Eduardo e ARTUR, Karen. (2006), “Reforma Trabalhista e Sindical: O Que Tivemos, o Que se Quer e o Que se Pode Ter", in D. Gros et alii (orgs.), Empresas e Grupos Empresariais: Atores Sociais em Transformação. Juiz de Fora, Ed. UFJF, pp. 187-188.

NORONHA, Eduardo, DE NEGRI, Fernanda e ARTUR, Karen. (2006). "Custos do Trabalho, Direitos Sociais e Competitividade Industrial”, in J. A. de Negri, F. de Negri e D. Coelho (orgs.), Tecnologia, Exportação e Emprego. Brasília, Ipea.

PIORE, Michael e SCHRANK, Andrew. (2006), “Trading Up: An Embryonic Model for Easing the Human Costs of Free Markets". Boston Review, vol. 31, no 5, pp. 11-14.

. (2008), "Toward Managed Flexibility: The Revival of Labour Inspection in the Latin World". International Labour Review, vol. 147, no 1, pp. 1-23. 


\section{Roberto Rocha C. Pires}

PIRES, Roberto. (2008a), “Compatibilizando Direitos Sociais com Competitividade: Fiscais do Trabalho e a Implementação da Legislação Trabalhista no Brasil". Texto para Discussão, no 1.354, Ipea.

. (2008b), "Promoting Sustainable Compliance: Styles of Labour Inspection and Compliance Outcomes in Brazil". International Labour Review, vol. 147, no 2-3, pp. 199-229.

POLINSKY, A. Mitchell e SHAVELL, Steven. (2000), "The Economic Theory of Public Enforcement of Law". Journal of Economic Literature, vol. 38, no 1, pp. 45-76.

PRESSMAN, Jeffrey e WILDAVSKY, Aaron. (1973), Implementation. Berkeley, University of California Press.

REISS JUNIOR, Albert J. (1984), "Selecting Strategies of Social Control over Organizational Life", in K. Hawkins e J. M. Thomas (eds.), Enforcing Regulation. Boston, Kluwer-Nijhoff Publishing.

SILBEY, Susan. (1981), “Case Processing: Consumer Protection in an Attorney General's Office". Law \& Society Review, vol. 15, no 3-4, pp. 849-881.

(1984), "The Consequences of Responsive Regulation", in K. Hawkins e J. M. Thomas (eds.), Enforcing Regulation. Boston, Kluwer-Nijhoff Publishing.

e BITTNER, Egon. (1982), “The Availability of Law”. Law and Policy Quarterly, vol. 4, no 4, pp. 399-434.

SIMON, Herbert. (1947), Administrative Behavior. New York, Macmillan. e MARCH, James. (1958), Organizations. New York, Wiley \& Sons.

STIGLER, George. (1971), “The Theory of Economic Regulation”. Bell Journal of Economic and Management Science, vol. 2, no 1, pp. 3-21.

TENDLER, Judith. (1997), Good Government in the Tropics. Baltimore/London, Johns Hopkins University Press.

THOMAS, John e GRINDLE, Merilee. (1990), “After the Decision: Implementing Policy Reforms in Developing Countries". World Development, vol. 18, no 8, pp. 1163-1181.

TULLOCK, Gordon. (1974), “Does Punishment Deter Crime?". The Public Interest, no 36, pp. 103-111.

VAN MAANEN, John. (1973), "Observations on the Making of Policemen". Human Organization, vol. 32, no 4, pp. 407-418.

WEIL, David. (2005), "Public Enforcement/Private Monitoring: Evaluating a New Approach to Regulating the Minimum Wage". Industrial and Labor Relations Review, vol. 58, no 2, pp. 238-257.

WILSON, James Q. (1968), Varieties of Police Behavior: The Management of Law and Order in Eight Communities. Cambridge, Harvard University Press.

. (1989), Bureaucracy: What Government Agencies Do and Why They Do It. Basic Books, Harper Collins Publishers.

ZYLBERSTAJN, Hélio. (2003), “Condomínio de Empregadores: Uma Solução Eficiente e Justa para Vínculos de Curta Duração", in J. P. Z. Chahad e M. C. Cacciamali (orgs.), Mercado de Trabalho no Brasil: Novas Práticas Trabalhistas, Negociações Coletivas e Direitos Fundamentais no Trabalho. São Paulo, LTR, pp. 157-189. 


\section{ABSTRACT \\ Enforcement Styles and Public Policy Outcomes: Labor Inspectors and Compliance with Labor Regulations in Brazil}

The article argues that variations in the outcomes of the same public policy can be explained by different practices and enforcement styles adopted by front-line bureaucrats. Based on extensive field research on the enforcement of labor legislation in Brazil, the author develops a typology of the outcomes of labor inspection in terms of levels of compliance with labor regulations in different economic activities. Findings from comparative analysis (across and within cases) indicate consistent associations between the enforcement style adopted by labor inspectors that combines sanctions with technical and/or legal assistance, and the reconciliation of labor rights with increased company performance and competitiveness.

Keywords: policy enforcement; bureaucracy; labor regulations

\section{RÉSUMÉ}

Styles d'Implantation et Résultats de Politiques Publiques: Les Inspecteurs du Travail et le Respect de la Législation du Travail au Brésil

Dans cet article, on avance que des différences dans les résultats d'une même politique publique peuvent s'expliquer à partir des différentes pratiques et styles d'implantation adoptés par des bureaucrates. Prenant appui sur une longue recherche sur le terrain concernant la mise en place de la politique $\mathrm{d}$ 'inspection du travail au Brésil, on pose une typologie de ses résultats quant au respect de la législation du travail dans diverses activités économiques. Des analyses comparatives révèlent des associations systématiques entre, d'un côté, l'adoption par les inspecteurs d'un style d'implantation qui associe sanctions et orientation technique et/ou légale et, d'un autre, l'harmonie des droits du travail avec de plus grandes performances et une compétitivité des entreprises.

Mots-clés: implantation de politiques publiques; bureaucratie; droits du travail 